Published in The Learning Organization, 2018, vol. 25, no. 2, pp. 92-101

which should be cited to refer to this work

DOI: https://doi.org/10.1108/TLO-03-2017-0033

\title{
Challenges to The Learning Organization in the Context of Generational Diversity and Social Networks
}

\section{Structured Abstract}

Purpose: To gain a better understanding of the challenges to the emergence of a learning organization (LO) posed by a context of generational diversity and an enterprise social networking system (ESNS).

Design/methodology/approach: This study employs a qualitative methodology based on an analysis of 20 semi-structured interviews in a high-tech organization, and internal company documents relating to the introduction of a new, centralized ESNS.

Findings: Our study uncovers fundamental differences between Generation X and Y employees regarding their ESNS adoption and use. While Xers take more time to adopt the new, centralized ESNS introduced into the company, their use seems in line with the company culture and corporate norms of behavior. At the same time, even if Yers are faster ESNS adopters, they use it as they use Facebook disregarding the hierarchy and organizational boundaries. This creates tensions between Generation $\mathrm{X}$ and $\mathrm{Y}$ and undermines the formation of the learning organization.

Research implications/limitations: Since our conclusions are specific to a context of a singleorganization, we recommend other case studies, to enrich the findings.

Originality/value: By highlighting how the use of social networks modifies who has the power and the control of knowledge in an organization, this paper enriches the theory on the learning organization. It has implications for managers wishing to design learning organizations in the context of intergenerational diversity.

Keywords: learning organization, generational diversity, enterprise social networking systems. Article Classification: Research paper. 


\section{Introduction}

The 1990 publication of The Fifth Discipline: The Art of Practice and the Learning Organization by Peter Senge marked the beginning of the popularity of the concept of the 'learning organization'. Defined in opposition to the traditional inflexible bureaucratic form, a consensus has emerged that the 'learning' (flexible, adaptable, capable of developing new knowledge) organization was the most desirable organizational form in face of increasing competitive pressure. However, Örtenblad (2002, p.88) notes that besides being biased to the positive aspects of the learning organization, most of the research has for a long time been stuck in the functionalistic paradigm of learning. The functionalistic paradigm, objectivistic and rooted in regulation and social order, assumed that managers decide who learns what and that knowledge that individuals acquire is shared and stored in 'organizational memory' (Hedberg, 1981). However, questions of power and control of knowledge in organizations have largely been ignored (Easterby-Smith et al., 1998). In spite of some recent developments (Örtenblad, 2013), many researchers continue to be stuck in the "old paradigm” and struggle to account for the contemporary organizational and environmental shifts.

Yet, 21st century organizations have at least two novel characteristics: increased generational diversity (Ellwart et al., 2012) and ubiquitous presence of social networks. Both of these factors modify the organizational context and pose additional challenges to the formation of the 'learning organization'. In short, younger knowledge workers are less loyal to their employers and more individualistic than are their older colleagues. These differences are reinforced by the younger generation's quasi-continuous use of social networks, which liberate them from the constraints of the hierarchy and grant them a larger power and control over knowledge. One of the consequences of this ubiquitous presence of social networks and intergenerational diversity may well be an impact on the way a collective memory is constructed amongst individuals in the organization. 
Research into SNs is increasing, owing to their increasing place in society (Park et al., 2009; Razmerita et al., 2014; Sawyer and Southwick, 2002). However, SN usage differences, specifically generational differences, and their impact on building the learning organization have been largely unexplored. In this research we adopt Örtenblad's (2002, 2013) pragmatic and radical perspective and consider that there is no one 'learning organization' type but that there are contextually specific different learning organization aspects, namely, learning at work, organizational learning, climate for learning and a learning structure. Our focus is that on the learning structure. In line with a radical paradigm of the learning organization, we ask: How do Xer and Yer knowledge workers differ in their ESNS uses? How do these differences influence control over knowledge in an organization?

\section{Generational Differences in Values, Work-related Attitudes and Social Network Use}

Gibson et al. (2009) highlight key intergenerational differences and intragenerational similarities. Xers are independent and value family-work balance (Kogan, 2001). They are more loyal to their employers than are their younger Yer colleagues. According to Anantatmula and Shrivastav (2012), Yers (a.k.a. the Internet Generation, iGen, or Net Generation) are ambitious, talented, and demanding (Baldonado, 2008). In the work context, they learn quickly and seek immediate gratification. In relationships with their colleagues and managers, they need much attention and immediate feedback. From the start of their careers, they seek high-profile jobs and flexihours, and seek to benefit from professional development programs (Sheahan, 2005). With technology making it possible to work anytime and anywhere, Yers seek autonomy and question traditional work structures. They are the why generation because they challenge the established order and do not hesitate to voice their (critical) opinions (Lyon et al., 2005).

Despite a growing consensus about the distinctness of different generations, Crumpacker and Crumpacker (2007) found that Xers and Yers are in some ways very similar, yet highlight that ICT use, a potentially key explanatory factor of generational differences, is under 
researched. While Xers and ICT have evolved together, Yers were born after computers came to be ubiquitous, coming of age with the Internet as a fact of life (Dolezalek, 2007). This familiarity with ICT causes Yers to have a different approach to their work, networking, and communicating with others (Pooley, 2006).

Twenge and Campbell (2008) found generational differences at psychological and technological levels, with the former strongly influencing workplace behaviors. Although Xers are highly adaptable to technology (Anantatmula and Shrivastav, 2012), Yers live in the world of SN and constant connectedness. According to Glass (2007), Yers are more at ease sending a quick e-mail or digital message with face-to-face discussion or picking up the phone. Similarly, McLester (2007) shows that Yers are multimedia-oriented - their work attitudes are strongly influenced by smartphones and games.

In their personal lives, Yers simultaneously use SNs to inform themselves, search for more attractive job opportunities, or share perspectives. In the workplace, they value the option of using SNs during work hours (Skoludova and Horakova, 2016), often bypassing formal communication channels. It seems that the virtual space of SNs provides the Yers with an unlimited source of knowledge and information. They navigate inside disregarding the line of command or the organizational boundaries. This often leads to intergenerational friction (DiRomualdo, 2006).

This is key because geo-dispersed organizations increasingly introduce internal SN tools to enhance knowledge sharing. Ongoing knowledge sharing between individuals is also a prerequisite for any company to become a learning organization, since knowledge obtained by individual employees (who may collaborate on a project or across interconnected projects) gradually transforms into organizational knowledge (Pemberton and Stonehouse, 2000; Juriado and Gustafsson, 2007). However, little is known about the differences in how Xers and Yers use SNs in an organizational context and how these differences influence control over 
knowledge. Our research question is therefore the following: How do intergenerational differences in values, work attitudes and SN use influence control over knowledge in an organization?

\section{Research Setting and Data Management}

Research setting and data collection

Our data comes from a case study analysis. Our case, ITSol (a pseudonym, owing to confidentiality), was established in France at the end of the 1980s. It is now a multinational IT solution provider with more than 14,000 employees from 118 nationalities. To enhance collaboration and knowledge sharing among employees, management at ITSol decided to integrate several ICT tools (e.g., Cisco Jabber for internal chats, MangoApps for collaboration, and CodinGame for recruitment and teambuilding) into one ESNS. It quickly appeared that adoption of the new SN was not homogenous throughout the organization; we decided to analyze this.

Our data collection took place between 2014 and 2016 in a division in the south of France. Our sources included 20 semi-structured interviews, internal documents, and media articles. We recruited 20 respondents via convenience sampling; we interviewed people who use ESNSs regularly at work, because they could best provide useful, relevant information and narratives that would help us understand the phenomenon (Glaser and Strauss, 1967; Patton, 1990).

\section{Data Management}

\section{Data collection}

We conducted 10 interviews with employees from marketing and sales departments who identified as Xers and 10 Yers, asking how they perceive the ways they adopt and use any ESN system in their work at ITSol.

The interviews lasted between 30 and 60 minutes. We encouraged the respondents to be as detailed, honest, and transparent as possible in revealing what they (dis)liked about ESN 
systems use at ITSol. We interviews until saturation and we began to notice redundancies in respondents’ answers (Guest et al., 2006; Mason, 2010; O’Reilly and Parker, 2013).

Data analysis

We transcribed the audio-recordings. We coded all the collected data, manually processing the data and information, and organizing it according to the aspects (Marshall and Rossman, 1999) that emerged. Each aspect was a meaningful sequence of words relating to Xers' and Yers' uses of and contributions to ESN systems. We ordered these aspects for analysis.

The qualitative data from the 20 respondents, which we converted into aspects, was displayed in a “conceptually clustered matrix” (Miles and Huberman, 1994, p. 127): The interactivity between the displayed data (aspects) and data reduction (the result of data redundancies) produced many more fine-grained aspects (Marshall and Rossman, 1999, p. 154). We applied Glaser and Strauss’s (1967) iterative approach to qualitative research, analyzing each aspect and comparing it to the others, to eliminate content redundancies. Where we found any redundancy between aspects, we merged similar aspects (Dey, 1993, p. 129).

Specifically, each aspect was formulated in a concise sentence, followed by a detailed explanation of how it positively or negatively impacted on adoption, contribution, and learning about how to collaborate on ESN systems with colleagues from the same or a different generation. In a final step, we grouped these multiple aspects into main categories (Dey, 1993, p. 94), capturing each category in a short descriptive sentence that included all the aspects relating to Xers and Yers' challenges of collaborating over - and of adopting and contributing to - ESN systems. The final result was four nonredundant categories: the attitudes of Xers in the face of ESNSs, the attitudes of Yers in the face of ESNSs, the tensions resulting from the generational differences, and the impact of ESNSs on knowledge coordination and control. We will now present these. 


\section{Findings}

The attitudes of Xers and Yers in the face of ESNSS

Our data suggest that Xers take more time than Yers to adopt a new ESNS because they value learning in-depth how these ESNSs work. Xers usually prefer mastering the current ESNS before they dig into another to figure out how it works. One Xer explained: “These babies [new ESNSs] can be time-consuming if I really want to learn how to operate them properly and efficiently. They’re not always as intuitive as we think’ (Béatrice, 41, Business and Operations Planning Manager). Another Xer said, “It’s learning-by-doing. If you don’t invest sufficient time in using the same platform, you'll never understand how the bloody thing works' (André, 43, Service Strategy Manager).

Another Xer trait that emerged is empathy toward colleagues who have long used the same ESNS; they feel it would be unfair to disrupt their daily operational routines by asking them to learn how to use a new ESNS. One Xer noted: 'I’m not too hot on trying so much new stuff [ESNSs] and to ask my colleagues to join me because, you know, people stick to the systems they usually use, and I think it would be too much of a pain and stress for them to expect them to switch' (Claudine, 49, Manager, Competitive Intelligence Corporate Strategy).

Some Xers resist switching to a new ESNS. Indeed, some of our Xers prefer exchanging via communication tools to which they can limit participation, usually to their team. In this way, Xers feel they keep control of these information flows and ensure not disrupting the organization's traditional functioning, so that employees can find the data - the information and knowledge they look for - easily and quickly.

In-depth learning about the technical functioning of ESNS is not top priority for some Yers. They feel more comfortable than Xers with not investing too much time in learning indepth new platform's functionalities. Because Yers are in business contexts in which little time passes before one switches from one IT tool to another, they think it not worth investing much 
time in knowing how a tool works in-depth because they will shortly use another or quit their present job and move to another company. A Yer recounted: ‘I usually don’t spend too much time figure out the whys and whats of an app someone here just released on our shared platforms. What's the point? Besides, I don’t think I'll stay here much longer.' (Maxime, 26, Customer Service Project Coordinator).

Some Yers expressed no commitment to the ESNS they were using. They would happily switch to another if they thought it more efficient to interact and share information with colleagues, or simply if they felt like experimenting with another ESNS. A Yer stated: 'The digital universe is filled with good stuff, and you win if you're lucid enough to choose the good stuff... the [digital tools, platforms] that gives you a competitive edge. It's just a matter of time before the smart ones also spot them and start using them too' (Nassim, 31, Change Management Team Assistant).

The tensions resulting from the generational differences

Our data reveals that Xers' perception is that Yers are too easily distracted because they are constantly 'connected'. An Xer noted: 'I get frustrated sometimes because some [Yers] use too many media [platforms] to communicate [with other company colleagues], and I totally understand this because they are young and curious, and also want to discover new things and people, and because they know very well how to figure out these [new platforms], but... it does backfire because you've got too much [information] flying all over the place, so it gets messy and sloppy’ (Serge, 56, Director of Business and Operations).

Some Xers complained about some Yers' 'lack of good manners' in how and with whom they share information in an ESNS. An Xer indicated, 'Some of us [Xers] complain that [Yers] sometimes lack etiquette on how to use [ESNSs]... They [Yers] don't follow a proper code of conduct, as I do... and this sometimes causes me to have to explain to them [Yers] how to use them properly’ (Katerina, 47, Innovation Promotion \& Culture Manager). Another Xer stated: 
'I'm not their [Facebook] friend... we're corporate, so let's stay corporate when we talk... or ask for something from each other... you can't just write to anyone and make spelling mistakes along the way...' (Muriel, 41, Knowledge Manager, NECSE Marketing Portfolio Management \& Operations).

Moreover, our data revealed that Yers tend to disclose more personal information and hesitate less to express their opinions or impressions. This has both a positive and a negative effect. The positive effect is that their honest and publicly transparent comments, suggestions, and complaints - as long as they are not biased by fear of political/managerial sanctions - lead to interesting discussions and improvements, especially when people give them feedback. Xers were also usually more reluctant to provide honest comments on a public virtual space because they are more concerned than Yers with not replying to comments that are politically inappropriate or not in line with corporate norms and values. So, Xers tend to not reply to such comments. The negative effect is that, since Yers crave feedback, this sometimes motivates other Yers to give their personal opinion on these (sometimes negative) comments, which can escalate into a negative spiral. This creates misunderstandings and tensions, which can only be resolved through inter-personal, face-to-face discussions. We found that, if supported by culture of trustful and open exchange, these discussions allow Xers to learn from Yers and vice versa.

\section{The impact of ESNSs on knowledge coordination and control}

The $\mathrm{Y}$ generation of knowledge workers is used to exploring SNs in search for information. One Yer claimed: 'It's easy just to throw out a question on the Internet. You'd post the same question on many chats, and you were sure someone would answer. You had to remember where you'd posted, that's the thing' (Maxime, 26, Customer Service Project Coordinator). A number of Yers felt comfortable using several ESNSs simultaneously; some had already learnt how to concurrently use several SN platforms as students. A Yer recounts: 
'If you want to produce good work, one source of information is not enough. I remember how much time I spent on student forums online and library databases and social media networks to get what I needed to do my assignments’ (Marine, 28, Strategic Planning \& Operations).

What helps Yers to remain active on several ESNSs is to constantly keep several apps open on their smartphone and switch between them, multitasking, without difficulty or losing track of the information they get from these apps. A Yer noted: 'No, I have no problem if I have to use different company social networks... maybe... because it's not too different from what I do with my iPhone. I'm messaging on WhatsApp, I listen to music, maybe [look at] a pic, go to Gmail, and so many other things I do at the same time, and I don’t feel I get lost' (Laura, 23, Assistant Buyer).

The manner in which Yers navigate the SN virtual space sometimes give Xers a feeling of "loss of control" over what their younger colleagues do, especially in relation to how and where they search for information they need to resolve their operational problems. As John, a 56-year-old Customer Relationship Manager recounted: 'Sometimes, when I see him [his Yer subordinate] chat on his computer, I wonder what he is not doing'.

\section{Concluding Remarks, Implications for Practice and Limitations}

Our paper contributes to the literature in several ways. We contribute to the literature on the link between generational diversity and the use of the SNs. Even if Crumpacker and Crumpacker (2007) claim that Xers and Yers are similar, they also highlight that ICT use, a potentially important explanatory factor of generational differences, is under researched. Our findings help to bridge this research gap by showing that, in a context of ESNS, there are adoption and use differences between Xers and Yers. Moreover, we show that compared to Xers, Yers were more experimental in their SN uses, in line with O’Bannon’s (2001) findings that Yers show high entrepreneurial spirit when confronting the adoption of new, still unutilized tools and gaining competences and mastery on how to exploit them effectively. Yers may be 
more experimental with digital tools because they have always lived in a globalized world (Timmermann, 2007), which makes them comfortable with virtual relationships that transgress organizational boundaries.

We also show that if Yers value opportunities to use SN-related digital tools at work (Skoludova and Horakova, 2016), they often bypass the formal communication channels. Yers use SNs to actively seek information they need, look for quick solutions, and aren’t afraid to experiment things and to ask other Yers to contribute. Our Yers were somewhat demanding, as Baldonado (2008) noted.

While multigenerational issues have been studied in teams (Ellwart et al., 2012) and projects (Anantatmula and Shrivastav, 2012), with inconclusive results, our findings shed some light on intergenerational discrepancies between Xers' and Yers' adoption and learning how to use ESNs. Specifically, our findings confirm age diversity’s negative impact on communication between team members (Zenger and Lawrence, 1989). Conversely, our findings don’t align with Roth et al. (2006), who found a positive impact. Further, Yers' familiarity with ICT, which we uncovered, cause Yers to have a different approach to their work, networking, and communication (Pooley, 2006), notably with Xers. This creates misunderstandings that managers can transform into effective learning opportunities. For example, we show that Xers perceive Yers as quick learners but ones with a tendency to zap from one information source to another, which often leads to waste of time and cognitive saturation owing to an excess of information. Here, through experience sharing, Yers learn from Xers how to prioritize organizational problems and how to exchange effectively with the hierarchy and with clients. More generally, Yers learn from Xers the behavior codes in a corporation allowing them to become more politically competent.

By focusing on an underexplored issue of intergenerational differences in the context of ESNS adoption and use, we also contribute to the 'learning organization' theory (Örtenblad, 
2013). More precisely, we highlight challenges to the formation of the 'learning organization' caused by a change in the knowledge coordination process. While in the pre-social network world, managers detained control over who learned what, in the social network-based world, knowledge coordination is a-hierarchical and, to a great extent, uncontrollable. This finding is in line with what Örtenblad (2002) calls a ‘radical paradigm of organizational learning’ where individuals learn as free actors and where power and control over knowledge is not automatically detained by managers. We found that the ESNS provided Yers with an unlimited virtual space where power is not linked to the hierarchical position but to the ability to navigate in the informational space.

Notably, there is an increased need for open and constructive communication between the two cohorts so as to reduce the risks of misunderstandings, which seems in line with age diversity’s negative impact on communication between team members, as Zenger and Lawrence (1989) noted in a non-digital context. In our view, communication approaches should vary depending on whether initiated by Xers and intended for Yers, or vice versa. When it is from Xers to Yers, we recommend using mentoring, i.e. Xers teaching to Yers the organization's tacit rules, hierarchy and culture. Mentoring should also concern a salient problem of today’s digital era - learning how to separate personal and professional spheres of life. For communication from Yers to Xers, we recommend reverse mentoring, i.e. Yers teaching Xers the communication codes in the digital space. To incentivize Yers to exchange knowledge on ESNS, managers should adapt internal communication systems and styles and should include interactive tools and games.

One major limitation of this research is that our results cannot be generalized, for two primary reasons. First, our study was conducted in a single organization (ITSol) in the IT industry. Data collection would have benefited from being conducted in multiple organizations of different sizes and from different industries. Second, our investigation could have gone 
further in studying the differences in the perceptions, adoptions, and uses of ESNSs depending on a respondent's function (within-X and within-Y) in the organization, thereby identifying potential discrepancies in perceptions relating to respondents’ professional expertise and status. For instance, do perceptions, adoptions, and uses of ESNSs to learn differ concerning whether the respondent has an administrative, engineering, middle-managerial, top-managerial, IT, marketing, or sales profile?

Lastly, the study of intergenerational learning related to ESNSs is still in an early phase and may become even more complex. Zers are about to enter the corporate labor market. Born around 2000, they are the brothers and sisters of Yers, or Xers' children. They will likely even differ from Yers in how they value, perceive, adopt, and use digital tools. A wider discrepancy spectrum in ESNS adoptions and uses (and digital tools, in general) may be expected, since Zers are about to knock on organizations’ doors.

\section{References}

Anantatmula, V. and Shrivastav, B. (2012), "Evolution of project teams for generation Y workforce”, International Journal of Managing Projects in Business, Vol. 5 No. 1, pp. 9-26.

Baldonado, A. (2008), Exploring Workplace Motivational and Managerial Factors associated with Generation $Y$, Northcentral University, San Diego, CA.

Crumpacker, M. and Crumpacker, J. (2007), "Succession planning and generational stereotypes: should HR consider age-based values and attitudes a relevant factor or a passing fad?”, Public Personnel Management, Vol. 36 No. 4, pp. 349-369.

Dey, I. (1993), Qualitative Data Analysis: A User-friendly Guide for Social Scientists, Routledge, London, UK.

DiRomualdo, T. (2006), "Viewpoint: geezers, grungers, genXers, and geeks: a look at workplace generational conflict”, Journal of Financial Planning, Vol. 19 No. 10, pp. 18-21.

Dolezalek, H. (2007), "University 2.0: the time has arrived for a new kind of virtual corporate university. Is your organization ready?”, Training-New York Then Minneapolis Then New York, Vol. 44 No. 8, p. 22. 
Easterby-Smith, M., Snell, R. and Gherardi, S. (1998), “Organizational learning: diverging communities of practice?”, Management Learning, Vol. 29 No. 3, pp. 259-272.

Eisner, S. (2005), “Managing generation Y”, S.A.M. Advanced Management Journal, Vol. 70 No. 4, pp. 4-15.

Ellwart T., Bündgens, S. and Rack O. (2012), "Managing knowledge exchange and identification in age diverse teams”, Journal of Managerial Psychology, Vol. 28 Nos. 7/8, pp. 950-972.

Gibson, J., Greenwood, R. and Murphy Jr, E. (2009), "Generational differences in the workplace: personal values, behaviors, and popular beliefs", Journal of Diversity Management, Vol. 4 No. 3, pp. 1-8.

Glass, A. (2007), “Understanding generational differences for competitive success”, Industrial and Commercial Training, Vol. 39 No. 2, pp. 98-103.

Glaser, B. and Strauss, A. (1967), The Discovery of Grounded Theory: Strategies of Qualitative Research, Wiedenfeld and Nicholson, London, UK.

Guest, G., Bunce, A. and Johnson, L. (2006), "How many interviews are enough? An experiment with data saturation and variability”, Field Methods, Vol. 18 No. 1, pp. 59-82.

Hedberg, B. (1980), "How organizations learn and unlearn”, In Nystrom P.C. and Starbuck W.H. (eds.) Handbook of Organizational Design, Oxford University Press, Oxford.

Horwitz, S.K. and Horwitz, I.B. (2007), "The effects of team diversity on team outcomes: a meta-analytic review of team demography”, Journal of Management, Vol. 33 No. 6, pp. 9871015.

Joshi, A., Dencker, J.C. and Franz, G. (2011), “Generations in organizations”, Research in Organizational Behavior, Vol. 31, pp. 177-205.

Joshi, A. and Roh, H. (2009), "The role of context in work team diversity research: a metaanalytic review”, Academy of Management Journal, Vol. 52 No. 3, pp. 599-627.

Juriado, R. and Gustafsson, N. (2007), "Emergent communities of practice in temporary interorganizational partnerships”, The Learning Organization, Vol. 14 No. 1, pp. 50-61. 
Knight, D., Pearce, C.L., Smith, K.G., Olian, J.D., Sims, H.P., Smith, K.A., and Flood, P. (1999), "Top management team diversity, group process, and strategic consensus”, Strategic Management Journal, Vol. 20 No. 3, pp. 445-465.

Kogan, M. (2001), “Bridging the gap”, Government Executive, Vol. 33 No. 12, p. 16.

Levit, A. (March 28, 2015), “Make way for generation Z”, New York Times, available at http:// www.nytimes.com/2015/03/29/jobs/make-way-for-generation-z.html (accessed 16 July 2017).

Lieber, L.D. (2010), “How HR can assist in managing the four generations in today's workplace”, Employment Relations Today, Vol. 36 No 4, pp. 85-91.

Lyon S., Duxbury, L. and Higgins, C. (2005), “Are gender differences in basic human values a generational phenomenon?”, Sex Roles, Vol. 53 Nos. 9/10, pp. 763-778.

Marshall, C. and Rossman, G.B. (1999), Designing Qualitative Research, 3rd ed., Sage, Thousand Oaks, CA.

Mason, M. (2010), "Sample size and saturation in PhD studies using qualitative interviews", Forum Qualitative Sozialforschung / Forum: Qualitative Social Research, Vol. 11 No 3, Art. 8, available at http://www.qualitative-research.net/index.php/fqs/article/view/1428/3027

(accessed 12 August 2017).

McLester, S. (2007), “Technology literacy and the MySpace generation”, Technology \& Learning, Vol. 27 No. 8, pp. 17-22.

Miles, M.B. and Huberman, A.M. (1994), Qualitative Data Analysis: An Expanded Sourcebook, Sage, Thousand Oaks, CA.

O’Bannon, G. (2001), “Managing our future: the generation X factor”, Public Personnel Management, Vol. 30 No. 1, pp. 95-110.

O’Reilly, M. and Parker, N. (2013), “Unsatisfactory saturation: a critical exploration of the notion of saturated sample sizes in qualitative research”, Qualitative Research Journal, Vol. 13 No. 2, pp. 190-197.

Örtenblad, A. (2002), “Organizational learning: a radical perspective”, International Journal of Management Reviews, Vol. 4 No. 1, pp. 87-100. 
Örtenblad, A. (2013), Handbook of Research on the Learning Organization, Edward Elgar Publishing Limited, Cheltenham, UK.

Park, N., Kee, K.F. and Valenzuela, S. (2009), "Being immersed in social networking environment: Facebook groups, uses and gratifications, and social outcomes”, Cyber Psychology \& Behavior, Vol. 12 No. 6, pp. 729-733.

Patton M.Q. (1990), Qualitative Evaluation and Research Methods, 2nd Ed. Sage, Newbury Park, California.

Pemberton, J.D. and Stonehouse, G.H. (2000), “Organisational learning and knowledge assets”, The Learning Organization, Vol. 7 No. 4, pp. 184-93.

Pettinger, Richard (2002), The Learning Organization, Oxford: Capstone.

Pooley, E. (2006), "Generation Y: how twenty somethings are changing the workplace", Canadian Business, available at: http://www.canadianbusiness.com/businessstrategy/generation-y-how-twentysomethings-are-changing-the-workplace/ (accessed 2 June 2017).

Razmerita, L., Kirchner, K. and Nabeth, T. (2014), "Social media in organizations: leveraging personal and collective knowledge processes", Journal of Organizational Computing and Electronic Commerce, Vol. 24 No. 1, pp. 74-93.

Senge, Peter M. (1990), The Fifth Discipline: The Art and Practice of the Learning Organization, New York: Doubleday.

Sawyer, S. and Southwick, R. (2002), “Temporal issues in information and communication technology-enabled organizational change: evidence from an enterprise systems implementation”, The Information Society, Vol. 18 No. 4, pp. 263-280.

Sheahan, P. (2005), “Generation Y: thriving (and surviving) with generation Y at work”, Hardie Grant Publishing, Victoria, Australia.

Skoludova, J. and Horakova, L. (2016), “The impact of motivating and stimulating generation $\mathrm{Y}$ employees on company performance”, 17th International Scientific Conference on Economic and Social Development, Warsaw, Poland, 20-21 October.

Strauss, W. and Howe, N. (1997), The Fourth Turning: An American Prophecy. Broadway Books, New York, NY. 
Timmermann, S. (2007), "What a difference a generation makes: how our life experiences shape our viewpoints and behaviors”, Journal of Financial Service Professionals, Vol. 61 No. 3, pp. 25-28.

Twenge, J.M. (2010), “A review of the empirical evidence on generational differences in work attitudes”, Journal of Business and Psychology, Vol. 25 No. 2, pp. 201-210.

Twenge, J.M. and Campbell, S.M. (2008), “Generational differences in psychological traits and their impact on workplace”, Journal of Managerial Psychology, Vol. 23 No. 8, pp. 862-77.

Zenger, T.R. and Lawrence, B.S. (1989), “Organizational demography: the differential effects of age and tenure distributions on technical communication", Academy of Management Journal, Vol. 32 No. 2, pp. 353-376. 